\title{
La Cerdanya i els ceretans en el marc de la Segona Guerra Púnica
}

\author{
Jordi Morera Camprubín ${ }^{1}$, Joan Oller Guzmán ${ }^{1}$, Oriol Olesti Vila ${ }^{1}$
}

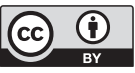

Rebut: 04/05/2020

Acceptat: 29/11/2020

\section{Resum}

En els darrers anys, les intervencions arqueològiques dutes a terme a l'àrea de la Cerdanya han identificat diverses evidències que permeten obtenir un major coneixement del poble històric dels ceretans. En aquest treball analitzarem aquelles que vinculen a aquests ceretans amb els fets succeïts durant la Segona Guerra Púnica i amb les seves conseqüències, principalment a través de les dades obtingudes al Castellot de Bolvir i al Tossal de Baltarga de Bellver de Cerdanya.

Paraules clau: Pirineus Orientals; Cerdanya; ceretans; Segona Guerra Púnica; Tossal de Baltarga; El Castellot

Abstract. Cerdanya and the Cerretanii in the Second Punic War

In recent years, archeological interventions in the Cerdanya area have identified several evidences that allow a greater knowledge of the historical people of the Cerretanii. In this work we will analyze the evidence that link these Cerretanii with the events that took place during the Second Punic War and with their consequences, mainly through the data obtained in the sites of Castellot de Bolvir and Tossal de Baltarga in Bellver de Cerdanya.

Keywords: Eastern Pyrenees; Cerdanya; Cerretanii; Second Punic War; Tossal de Baltarga; El Castellot

Morera Camprubí, Jordi; Oller Guzmán, Joan; Olesti Vila, Oriol. «La Cerdanya i els ceretans en el marc de la Segona Guerra Púnica». Treballs d'Arqueologia, 2020, núm. 24, p. 107-126. DOI: $10.5565 / \mathrm{rev} / \mathrm{tda} .114$

Les recents campanyes d'excavació dutes a terme pel grup de recerca PATCA a la Cerdanya han permès incrementar de forma substancial el nostre coneixement al voltant dels pobles històrics que habitaren aquest territori en èpoques passades. ${ }^{2}$

1. Universitat Autònoma de Barcelona. Àrea d'Història Antiga. Departament de Ciències de l'Antiguitat i l'Edat Mitjana. Arqueòlegs.cat. jordi.morera@uab.cat; joan.oller@uab.cat; oriol.olesti@uab.cat

2. El grup de recerca PATCA (Poblament i Territori a la Cerdanya Antiga) està dirigit pel Prof. Oriol Olesti Vila des de l'àrea d'Història Antiga del Departament de Ciències de l'Antiguitat i l'Edat Mitjana 


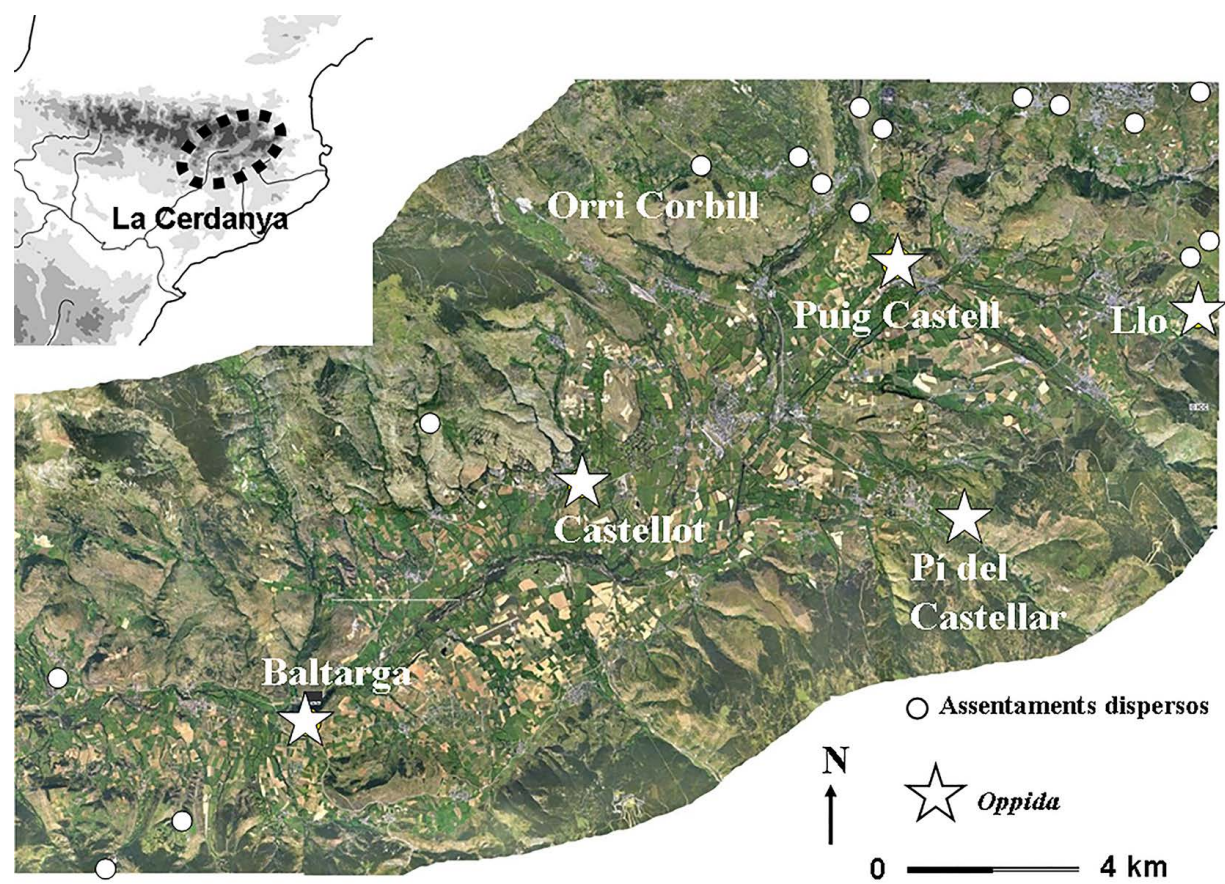

Figura 1. Situació dels principals assentaments arqueològics d'època antiga a la Cerdanya (font: autors).

Concretament, la investigació s'ha centrat en l'estudi del període antic i del poble que habitava a la zona en aquest moment: els ceretans. Gràcies a aquesta recerca, i a la d'altres grups que treballen als Pirineus Orientals, una ètnia com la dels ceretans, poc coneguda i escassament referenciada a les fonts, ha començat a emergir amb totes les seves característiques socioeconòmiques, culturals i territorials. $^{3}$

En aquest article centrarem els nostres esforços a intentar aportar dades al voltant dels processos històrics que afectaren els ceretans i el seu territori en el primer contacte intens amb les potències mediterrànies del moment (Roma i Cartago) en el marc de la Segona Guerra Púnica. Resulta evident que existí un impacte a causa del pas de les tropes cartagineses pels Pirineus, però avui en dia encara no hi ha un acord científic al voltant del punt de pas exacte d'aquestes. Per tant, creiem que dades arqueològiques procedents d'una zona com la Cerdanya poden aportar elements interessants a aquest debat.

de la Universitat Autònoma de Barcelona i està finançat per la Generalitat de Catalunya. Per a dur a terme les intervencions arqueològiques també s'ha comptat amb el suport financer del Ministerio de Cultura i de la Diputació de Girona.

3. Per un resum de les principals fonts literàries vinculades als ceretans, veure: Morera (2017: 70-140). 
Com veurem, encara no podem parlar d'evidències indiscutibles, però creiem que els resultats arqueològics dels treballs a jaciments com El Castellot de Bolvir i el Tossal de Baltarga de Bellver de Cerdanya, permeten fer hipòtesis sobre una repercussió directa d'aquests fets militars a la regió.

\section{L'evidència arqueològica: el Castellot de Bolvir}

El jaciment del Castellot de Bolvir, situat al mig de la plana cerdana, controlant les principals vies de comunicació que la travessen, consisteix en un oppidum configurat a la segona meitat de segle IV aC. Està organitzat a partir d'un potent sistema defensiu i d'un urbanisme complex al seu interior. La delimitació de l'assentament s'efectua amb una potent muralla de poc més d'un metre i mig d'amplada, realitza$\mathrm{da}$ amb còdols de mides diferents lligats amb fang. Aquesta muralla no és una senzilla barrera de traçada lineal, sinó que en els seus extrems s'observa un arquejat que es projecta uns $20 \mathrm{~m}$ en direcció nord, abraçant l'assentament. Just davant existeix un fossat defensiu d'entre 8 i $10 \mathrm{~m}$ d'amplada, que talla transversalment la terrassa. Finalment, el sistema defensiu quedaria complementat molt probablement per la presència d'una torre a l'extrem de llevant del front defensiu. La seva funció principal podria ser la de defensar l'entrada al poblat, situada al final de la muralla en aquell mateix sector, a uns $15 \mathrm{~m}$ darrere la torre.

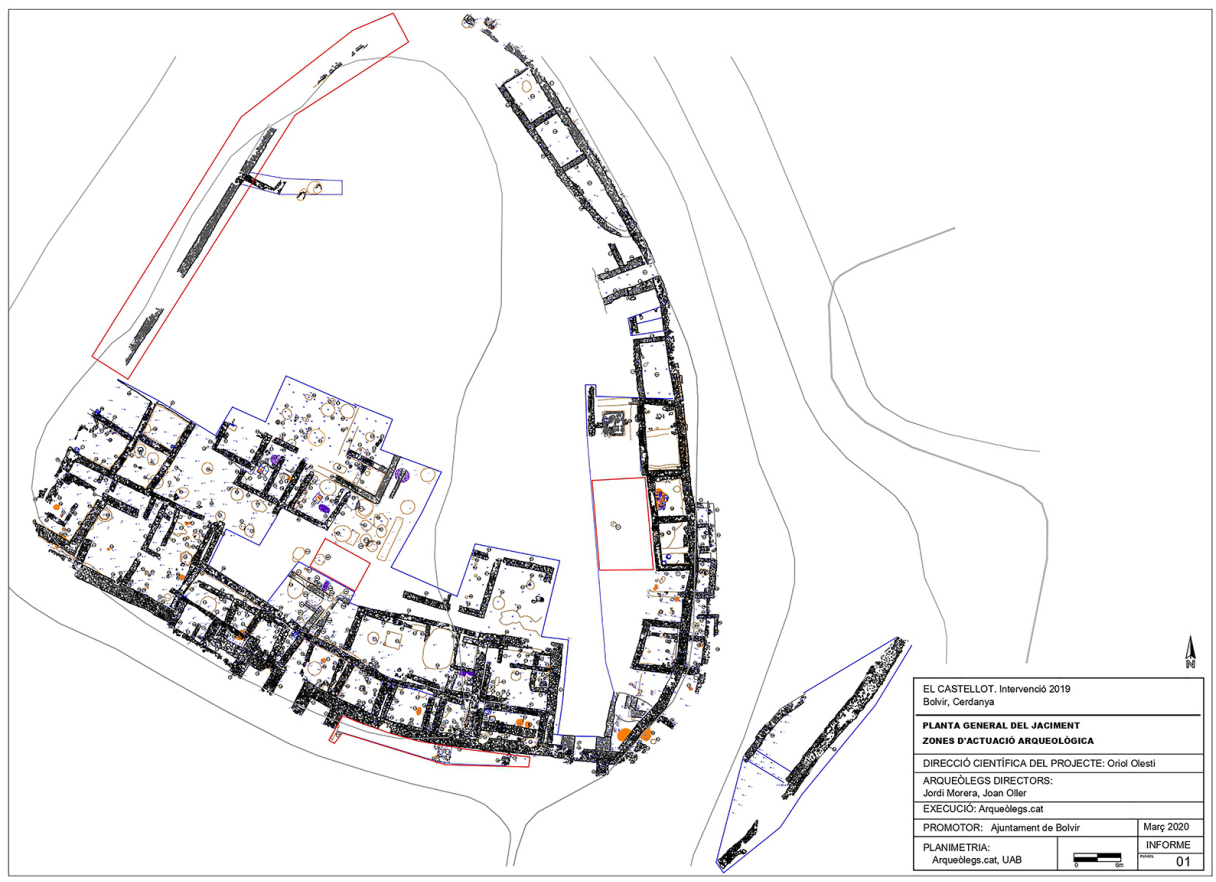

Figura 2. Planta del jaciment del Castellot de Bolvir (font: autors). 
Pel que fa a l'urbanisme del seu interior, fins al moment s'han pogut documentar 15 unitats domèstiques, totes elles situades radialment unes al costat de les altres, just adossades a la muralla o en el límit topogràfic de l'assentament. Exceptuant unes poques variacions, totes elles mostren una mateixa organització, amb dues estances concatenades. La primera, configurada com un pati obert o semiporxat, i la segona i posterior, on es desenvoluparien les activitats habitacionals més familiars i domèstiques. Com dèiem, en un parell de casos s'observa una divisió de la sala principal i en un tercer, possiblement a causa de les particulars funcions de la casa que es poden relacionar amb signes de ritualitat, la configuració és a partir de tres estances. Quant a la zona central del poblat, fins al moment només s'ha pogut identificar el que sembla un camp de sitges, i algunes poques estructures inconnexes. ${ }^{4}$

Cronològicament, com dèiem, l'assentament inicia la seva principal fase constructiva al segle Iv aC (tot i que hi ha evidències d'una ocupació al Bronze Final/Primer Ferro) i evoluciona fins a finals del segle III, quan s'experimenten un conjunt de canvis que portaran cap a una reforma generalitzada del nucli a mitjan segle II aC, donant inici a la fase romana republicana. És precisament en aquestes transformacions de finals del segle III i inicis del II on podem analitzar les possibles implicacions dels fets de la Segona Guerra Púnica sobre els ceretans i els seus assentaments.

Així, podem parlar dels canvis experimentats en el sistema d'emmagatzematge del poblat, fonamentalment en les seves sitges. De moment s'han excavat un total de 37 sitges al Castellot, totes d'època antiga. Per la seva tipologia es poden dividir en quatre grans grups, els quals, a grans trets, també porten associada una cronologia diferent. De forma general, podem detectar un increment gradual de les dimensions de les sitges $i$, a partir de l'anàlisi dels materials ceràmics recuperats, dos grans moments d'obliteració: un centrat al voltant de l'any $200 \mathrm{aC}$ i l'altre al voltant de mitjans de segle II aC.

En resum, comptem amb quatre grups de sitges al Castellot que es diferencien a partir de la seva morfologia, però també a partir de la ubicació a dins del jaciment. Aquelles més petites corresponen a la primera fase del jaciment, i s'haurien amortitzat al llarg del segle III aC (sitges 216, 453, 476, 828 i 999). La majoria s'emplacen a l'interior de les unitats domèstiques (ja sigui a la sala principal o al pati capdavanter) i presenten unes dimensions relativament petites. Són uns cossos bàsicament cilíndrics que no excedeixen els $1.4 \mathrm{~m}$ de fondària, ni els $2 \mathrm{~m}^{3}$ de capacitat volumètrica. Un segon grup de sitges tindria la seva aparició i amortització a finals de segle III aC (sitges 9, 189, 370, 830, 956, 5018, 5051 i 5056). Morfològicament tenen una clara evolució, ja que es fan més tubulars, lleugerament bicòniques en el perfil $\mathrm{i}$ amb unes fondàries que ronden els 1,7 i 1,9 m. Per tant, ocupant un volum que ja podria arribar als $3 \mathrm{~m}^{3}$. En aquest moment ja s'observa una ocupació clara de l'espai exterior, potser comunal, com ho demostra que tres d'elles s'ubiquen fora dels àmbits habitacionals.

4. Per dades detallades sobre el Castellot de Bolvir i sense ànim d'exhaustivitat, remetem a les publicacions més recents: De León et al. (2017), Morera et al. (2016, 2017), Olesti et al. (2011, 2018), Oller et al. (2018a). 


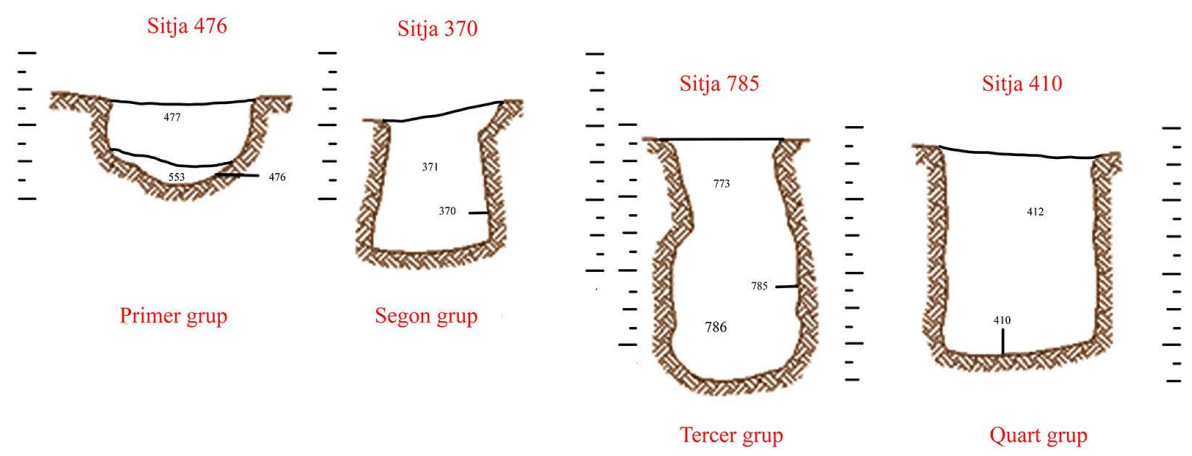

Figura 3. Exemple de la secció de cada grup de sitges del Castellot (font: autors).

Un tercer grup de sitges encara serien de majors dimensions, amb unes amplades que encara ronden els 1,5-1,7 m, però unes fondàries que oscil.len entre els 2,3 i els 3,3 m Tenen una forma bàsica- ment cilíndrica però un xic bombada, amb el fons pla, i presenten uns volums d'entre els 4 i $5 \mathrm{~m}^{3}$. Cronològicament, s'adscriuen en un període comprès entre finals de segle III aC i el tercer quart de

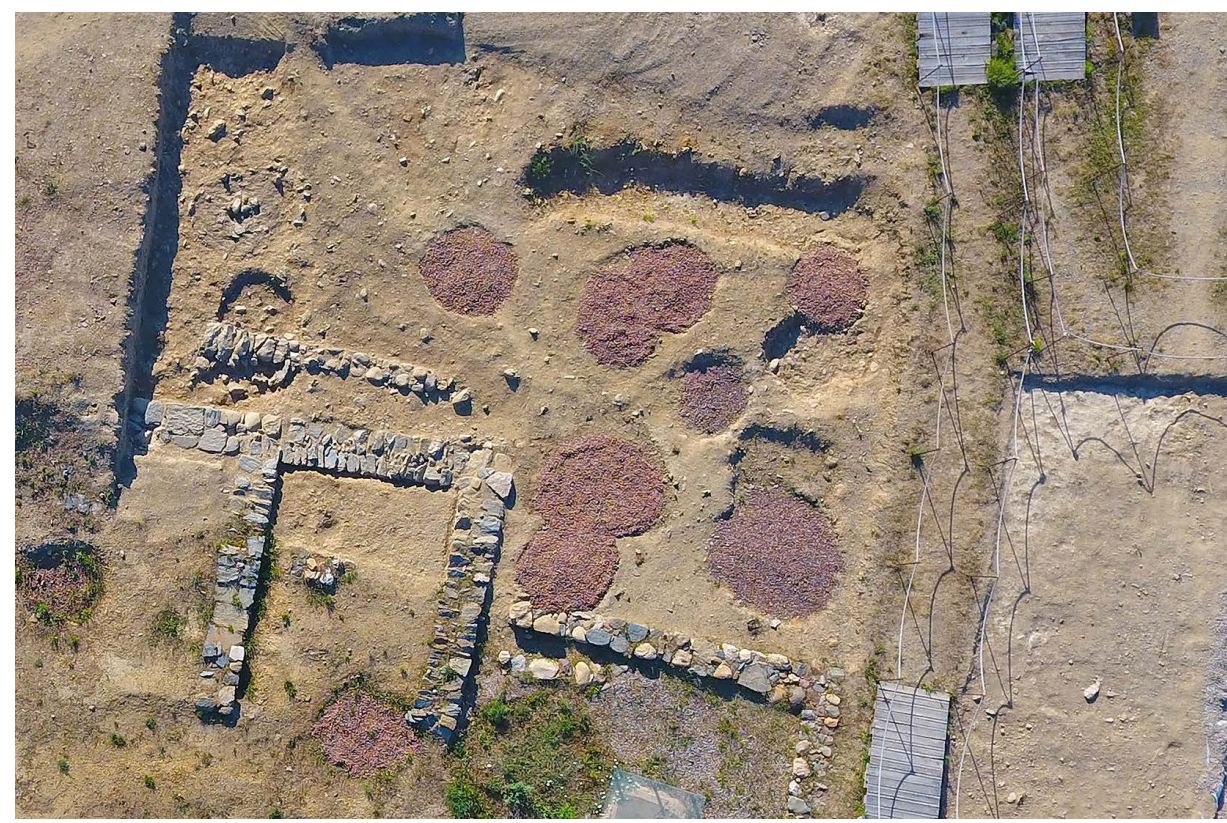

Figura 4. Vista aèria de la zona central del jaciment del Castellot. En vermell, algunes de les sitges excavades (font: autors). 
segle II aC. De totes maneres, dins d'aquest ampli ventall ens ha semblat observar dos subgrups. El primer subgrup estaria format per les sitges, 200, 206, 769 i 933, i es correspondrien a un moment al voltant del $200 \mathrm{aC}$. El segon subgrup, serien les sitges 24, 25, 757, 775, $785,902,908,983,991$ i 2241, i s'haurien de situar en el marc de les reformes de mitjans de segle II aC. Totes aquestes ja són de dimensions realment importants, adoptant un perfil globular que aconsegueix sobrepassar, amb escreix, els 2,5 m de fondària, i unes capacitats que, com dèiem, podrien arribar als $5 \mathrm{~m}^{3}$ en algun cas. Per tant, són unes sitges que tenen una clara evolució, doblant la capa- citat que tenien en la centúria anterior, senyal inequívoca, d'altra banda, de que els rendiments agrícoles també haurien augmentat. I una altra dada interessant és que, tot i que algunes encara es realitzen a l'interior dels espais privats (sitja 757), la gran majoria s'ubica a la zona exterior dels Àmbits I, II, III, on després s'hi ubicarà l'Edifici IV, esdevenint una mena de petit camp de sitges.

I finalment, l'últim grup són unes grans sitges cilíndriques de dos metres de diàmetre i unes fondàries d'entre 2,4 i 2,7 m (sitges 410, 709 i 5034). Presenten un perfil bàsicament cilíndric i ofereixen una volumetria que ronda els $8 \mathrm{~m}^{3}$. En els tres casos la cronologia d'amortit-

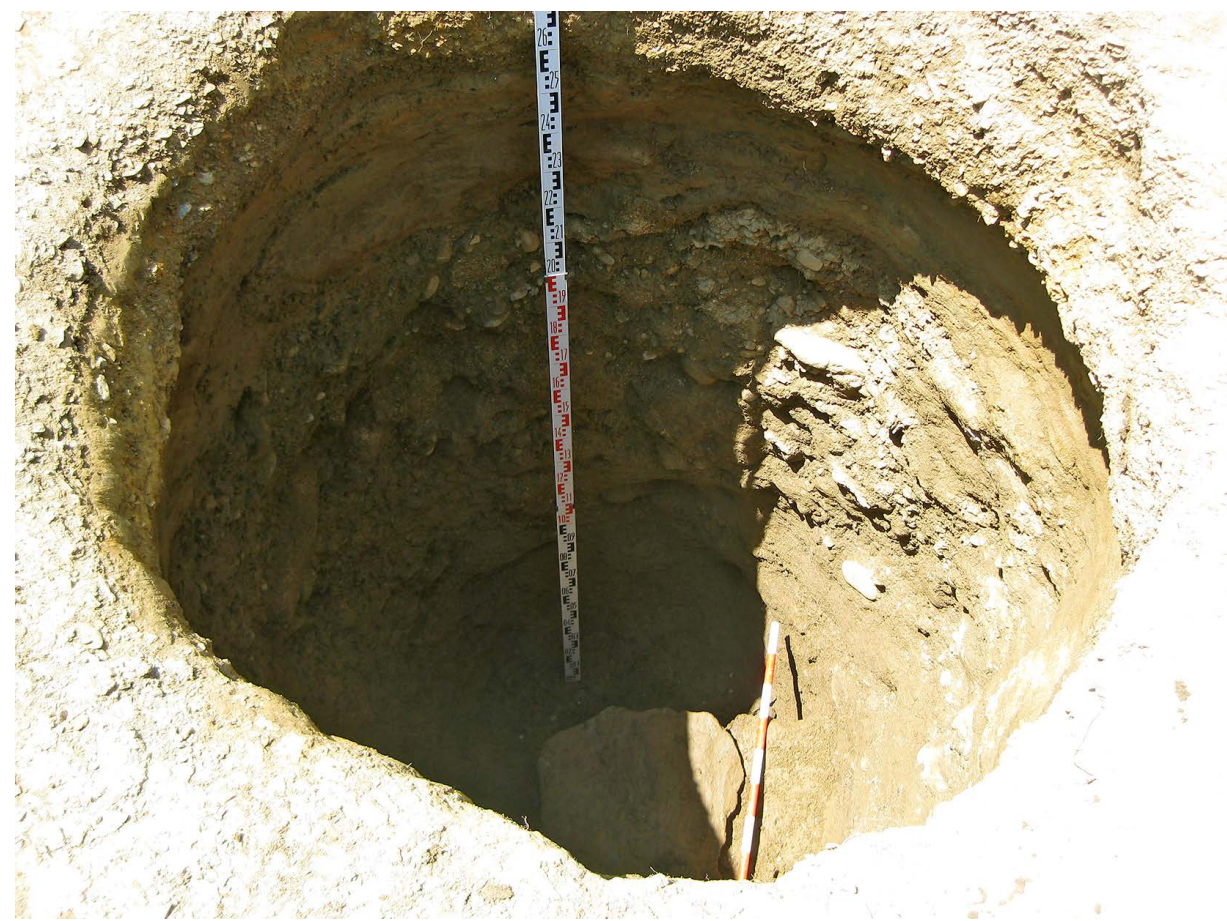

Figura 5. Sitja 25 del Castellot al final de l'excavació. Exemple de sitja vinculada al segon grup tipològic (font: autors). 
zació s'hauria de situar a la segona meitat de segle II aC, possiblement en el marc de les reformes republicanes. Consistirien en l'últim esglaó dins l'evolució tipològica dels dipòsits, ja que s'aconsegueix arribar a unes capacitats que tripliquen les que tenien les sitges una centúria enrere.

Evidentment, pel que fa al nostre interès concret, els grups tipològics més rellevants serien el segon i el tercer, ja que presenten evidències d'una possible amortització al voltant del $200 \mathrm{aC}$, en un context molt proper als fets de la Segona Guerra Púnica i que podria estar reflectint l'afectació que, des d'un punt de vista socioeconòmic, tingué la inestabilitat generada per aquest conflicte en el territori ceretà.

\section{L'evidència arqueològica: el Tossal de Baltarga}

Sens dubte, però, el jaciment que ha permès un major salt qualitatiu pel que fa al coneixement d'aquest període concret de finals del segle in al territori ceretà és el Tossal de Baltarga. Se situa a tocar del poble de Baltarga (el qual està situat al peu del tossal homònim), localitzat a uns tres quilòmetres a llevant del nucli poblacional de Bellver de Cerdanya, cap del terme municipal i també de la subcomarca de la Batllia. El Tossal de Baltarga constitueix el pujol més elevat del Serrat de la Pubilla i es troba ubicat a la seva part central, elevant-se fins a una altitud 1.166 metres snm.

El jaciment presenta dues fases cronològiques, amb una ocupació en època iberoceretana (s. IV-III aC) i una altra de romana republicana (s II-I aC). Es tracta d'un petit punt de guaita (de moment unes $0,3 \mathrm{ha}$ ) amb clara funció de control del territori i que, en època ceretana, consistia en un conjunt d'estructures isolades a la part més alta del turó, complementades amb diversos edificis col-locats en bateria, seguint la vessant d'aquest i sense cap tancament perimetral o muralla. De fet, fins al descobriment del primer d'aquests edificis en bateria (Edifici D), la fase ceretana del jaciment era molt poc coneguda, ja que les estructures a la part alta del turó presentaven un estat de preservació molt precari i, normalment, estaven destruïdes de forma parcial o total per les estructures d'època republicana. ${ }^{5}$

Precisament aquest conjunt d'edificis (D, F i G) són els que han aportat una petita revolució pel que fa al coneixement d'aquest moment concret de la història del territori ceretà. Es tracta de l'espai més ben preservat del jaciment, ja que el fet de les estructures estiguin retallades a la roca, formant una mena de calaix en el terreny i evitant l'erosió del pendent, ha permès la conservació de més d'un metre d'estratigrafia en la major part d'edificis. A això, hi hem d'afegir el fet fonamental que aquests edificis van ser destruïts de forma violenta, de tal manera que s'han conservat els darrers nivells d'ús i materials domèstics in situ. Això és especialment rellevant si tenim en compte, com veurem, que totes les evidències cronològiques (datacions radiocarbòniques, conjunt ceràmic i numismàtic) apunten a un moment de destrucció vinculat al darrer terç del segle III aC; per tant, coincidint plenament amb els fets de la Segona Guerra Púnica. Per tot plegat, analitza-

5. Per les dades arqueològiques del Tossal de Baltarga, veure: Oller et al. (2013), Morera et al. (2016), Olesti et al. (2016), Morera (2017), Morera et al. (2017), Oller et al. (2018a), Oller et al. (2018b). 


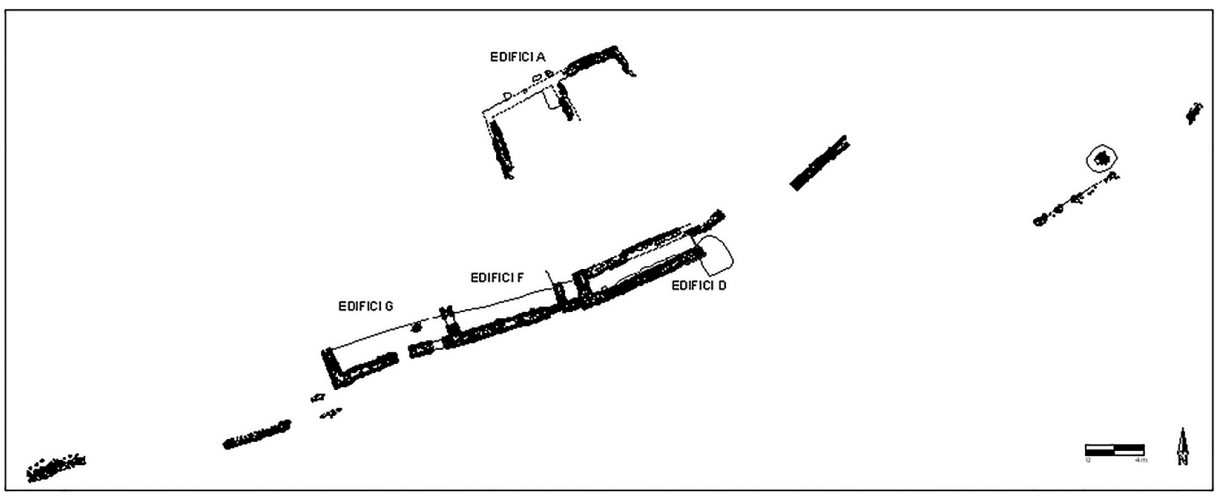

Figura 6. Planta de la fase ceretana del Tossal de Baltarga (font: autors).

rem amb detall les dades obtingudes en aquests espais. ${ }^{6}$

Aquest conjunt d'edificis (D, F i G) es van construir conformant una mena de barri de cases seguint el relleu del vessant del turó a partir d'un retall en el substrat rocós del tossal, en el qual s'encabiren. El primer és l'Edifici D. De planta rectangular, s'hi evidencien dues fases, la més antiga identificable amb el moment iberoceretà. El fet interessant, com dèiem, seria que aquesta fase va finalitzar de forma violenta amb una destrucció per incendi que va permetre segellar els nivells d'ocupació. La seva excavació permeté reconstruir l'existència d'un edifici de dos pisos de força potència i que s'adaptava a la morfologia del terreny. Així, l'enderroc de l'edifici permeté recuperar les restes carbonitzades tant del sostre com de les bigues que el mantenien. A la vegada, també es pogueren recuperar evidències del sòl del primer pis, probablement un punt d'hàbitat, situades a sobre el terra de la planta baixa i amb una important con- centració de materials ceràmics (la vaixella de la casa) i una concentració de granes de blat, segurament provinents de sacs d'emmagatzematge. A la planta baixa també es trobaren altres elements interessants. Així, es pogué identificar l'accés al costat est de l'edifici (amb restes encara de la porta carbonitzada), també grans contenidors ceràmics o les restes òssies d'un gos que morí durant l'incendi. Tot plegat mostra un edifici d'una certa rellevància $i$ una estructura complexa, $a m b$ una potencial funció d'hàbitat, lloc d'emmagatzematge i, per la seva situació, potser també de guaita.

Pel que fa al material, es recuperà un magnífic lot de ceràmica amb diverses peces senceres, sis fusaioles i un pondus i materials metàl-lics com dues anelles, un punxó de ferro amb mànec d'os o un ratllador també de ferro. Cal remarcar que la majoria d'aquests materials es trobarien associats als nivells del primer pis, reforçant la hipòtesi d'un espai vinculat a l'hàbitat. La datació del conjunt seria defini-

6. Volem remarcar que durant les campanyes de 2018 i 2019 es varen identificar restes de possibles nous edificis a l'oest de l'Edifici G. Per tant, podria ser que en les properes campanyes s'incrementés el nombre d'estructures vinculades a aquesta zona en època ceretana. 


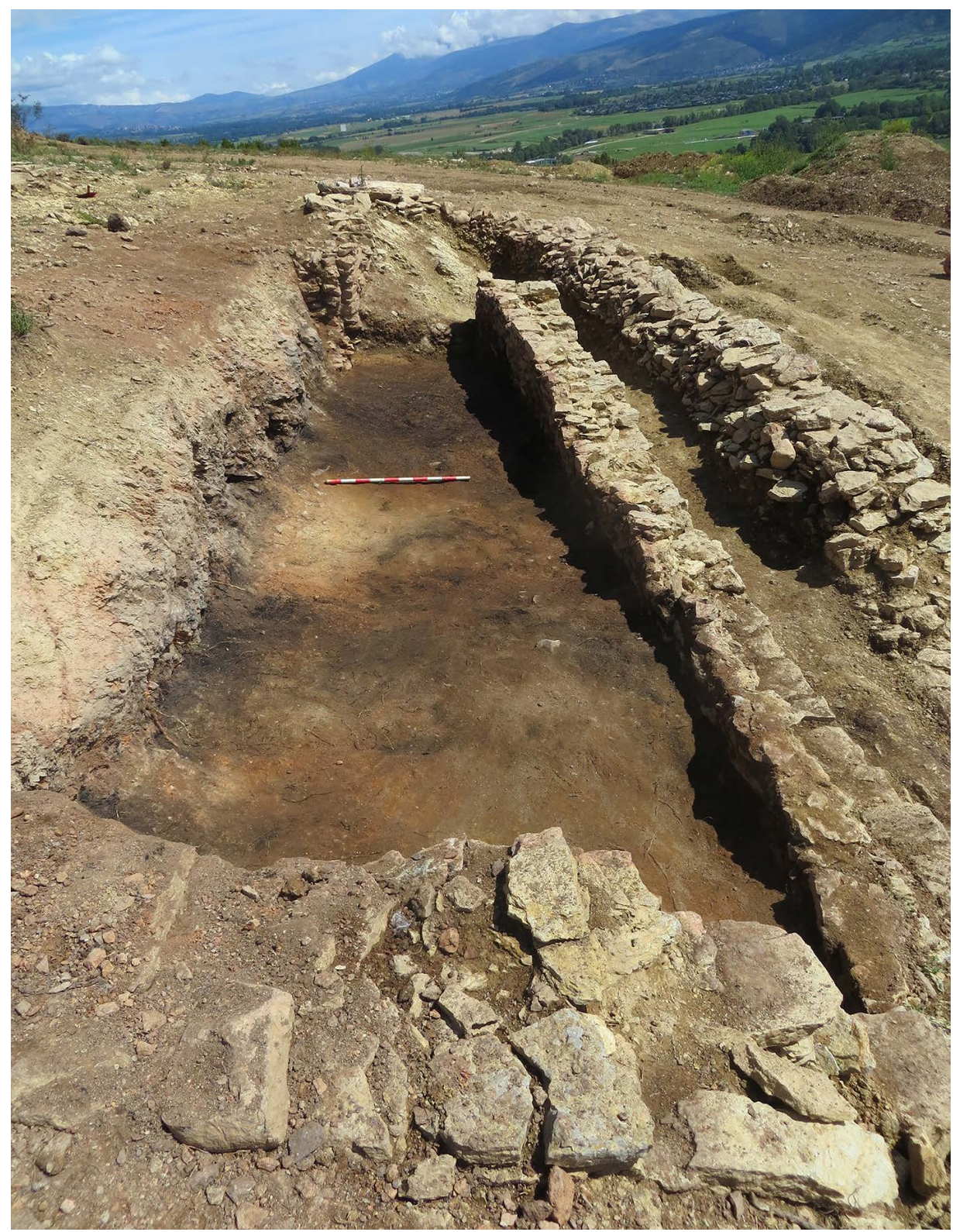

Figura 7. Imatge de l'Edifici D de Baltarga on es poden apreciar els nivells incendiats (font: autors). 


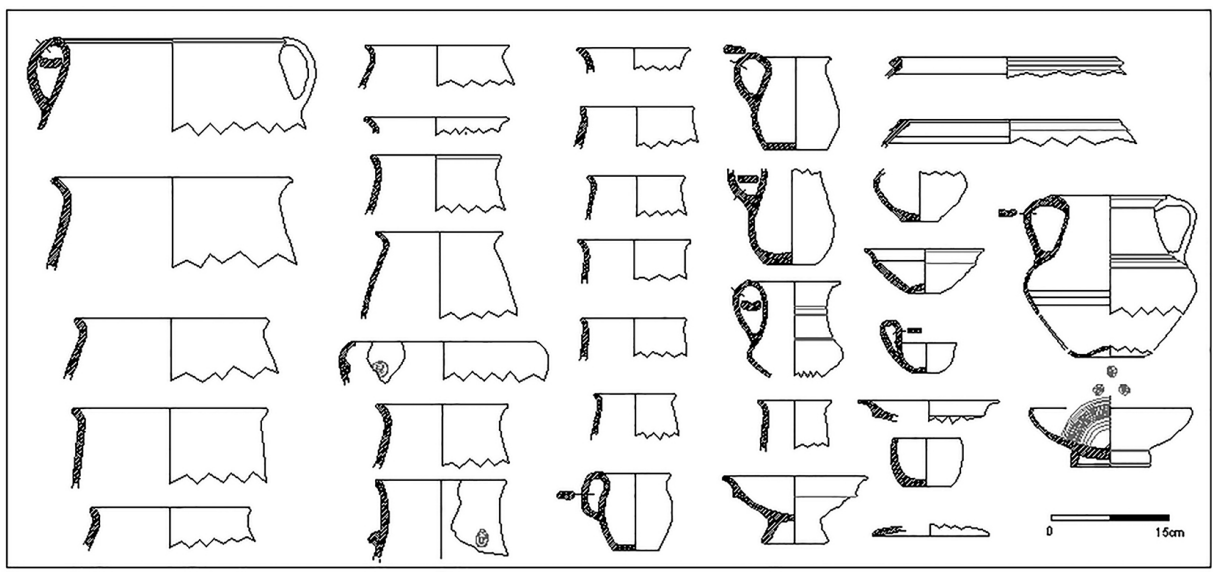

Figura 8. Material ceràmic recuperat a la fase ceretana de l'Edifici D de Baltarga (font: autors).

da per la troballa d'una copa de vernís negre de la Forma 26 del Taller de les tres palmetes radials de Roses, del segle III aC, i que arriba fins al darrer quart d'aquesta centúria. ${ }^{7}$ Aquesta cronologia ha estat confirmada per una datació radiocarbònica realitzada a partir d'unes granes de blat carbonitzades recuperades als nivells de destrucció, el resultat de la qual és de cal BC 385-200 (amb un 95\% de probabilitat), mentre que la datació sense calibrar seria de $230 \pm 30 \mathrm{BC}$. Tot i que el marge que ofereix és ampli, considerem molt significativa la coincidència pràcticament total entre la datació radiocarbònica convencional i la que ofereix el material ceràmic, situant, com dèiem, la destrucció d'aquest edifici molt probablement en el marc dels conflictes geopolí- tics de la Segona Guerra Púnica. ${ }^{8}$ L'edifici es reconstruiria en època republicana.

En el cas de l'Edifici F, se situa just al costat oest del D. Es tracta d'una estructura similar a l'Edifici D, de forma rectangular i de dimensions estretes (vuit metres de llargada per 1,5 metres d'amplada). L'accés al mateix se situaria en la seva part frontal, a la cantonada sud-est, i tindria un marxapeu de lloses planes per facilitar l'entrada. En aquest cas, no es pogué arribar a comprovar l'existència de dues plantes, ni tampoc comprovar la seva estructura interna amb detall, ja que la meitat de l'estructura es trobava sobreposada amb la posterior casa republicana. De la mateixa manera que a l'Edifici D, la fase ibèrica acabà amb una destrucció violenta, de tal manera que es pogueren re-

7. Semblaria que la producció dels tallers de Rhode aniria en franca davallada en l'últim quart de segle iII $\mathrm{aC}$ i la presència de les peces en els jaciments queda totalment desplaçada per les ceràmiques Campanianes A al voltant de l'any $200 \mathrm{aC}$ (Principal i Asensio, 2006: 122). Aquest fet ens determina una relació d'anterioritat força precisa. D’altra banda, la presència de les ceràmiques del Taller de Roses ha estat motiu suficient per datar moltes estructures al llarg del segle III aC, com alguns dels nivells més antics de Sant Esteve d'Olius (Asensio et al., 2008: 158) o de Puig Castellet de Lloret de Mar (Pons i Llorens, 1991), per posar només alguns exemples.

8. Anàlisi radiocarbònica realitzada pel laboratori Beta Analytic de Miami. 


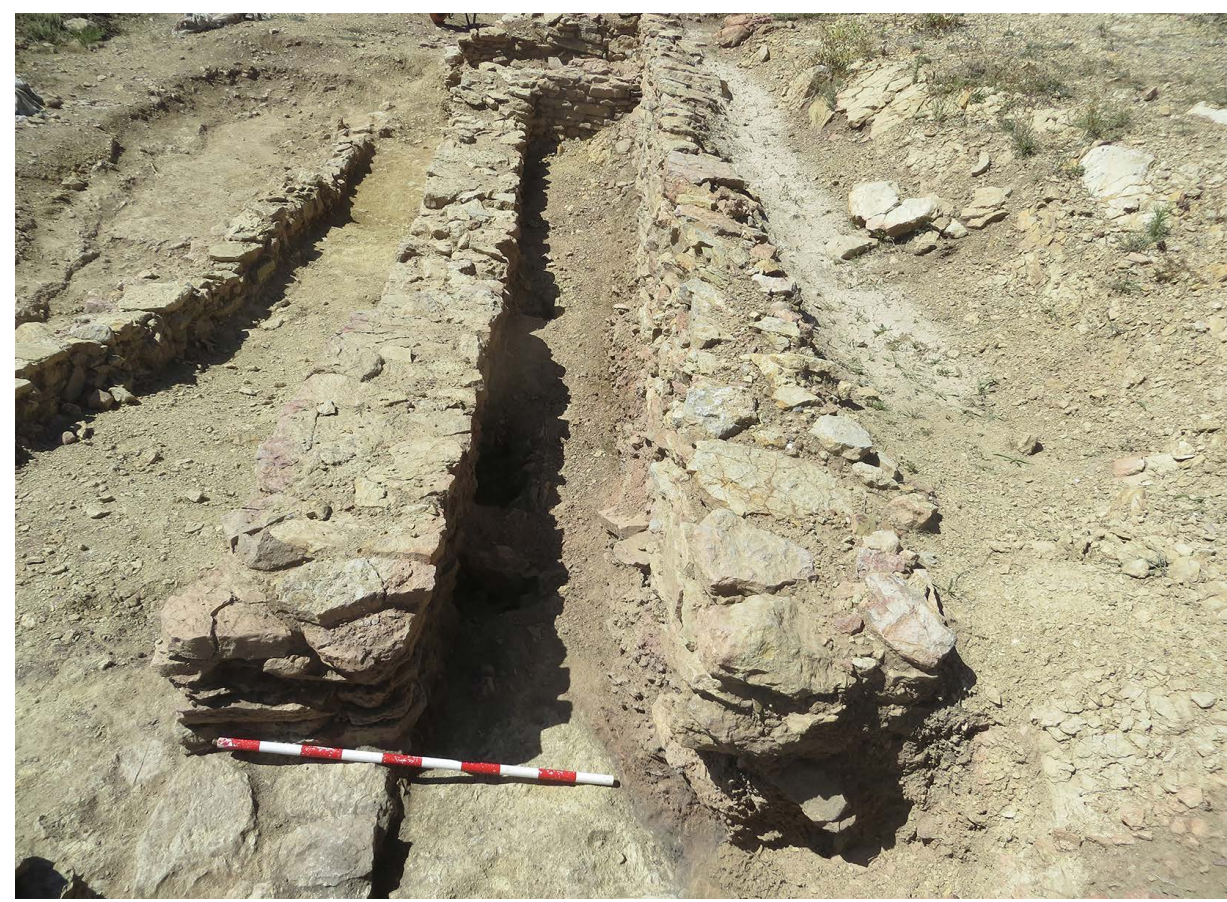

Figura 9. Imatge de l'Edifici F de Baltarga un cop finalitzada la seva excavació (font: autors).

cuperar nombrosos materials in situ. L'edifici estava lligat a un reduït espai contigu entre ell mateix i l'Edifici D, de funcionalitat indeterminada, el mur sud del qual s'adossaria al mur de tancament de l'Edifici D. Aquesta seria la millor evidència disponible fins al moment de l'existència de dues fases ibèriques a l'assentament. En època republicana hi hauria una refacció d'aquest edifici que se sobreposaria a les estructures ceretanes.

Finalment, en el cas de l'Edifici G, seria un altre espai associat a aquest habitatges situades en el retall en el geològic seguint la corba del vessant del turó. De la mateixa manera que els edificis $\mathrm{D}$ i F, patí una destrucció a final de la fase ibèri$\mathrm{ca}$, però en aquest cas no es donà una reconstrucció en època republicana, la qual cosa permeté excavar tots els nivells ibèrics sense intrusions posteriors. Es tracta, de nou, d'un edifici rectangular de dimensions estretes (set metres de llargada per dos metres d'amplada). En aquest cas, però, la documentació de diversos elements de brancatge, bigues de fusta i restes de paviment indiquen que es tractava d'una estructura de dues plantes. L'entrada de la planta baixa se situaria en el mur sud, lleugerament desplaçada cap a la cantonada sud-est. Els nivells relacionats amb la primera planta permeteren associar-la, sense massa dubtes, a un espai vinculat a l'hàbitat. En el costat est es recuperà un abundant lot de pondera, que permetrien parlar d'una compartimentació on se situaria un teler vinculat a la producció tèxtil. En el costat oest, en can- 
vi, aparegué una concentració de material ceràmic molt remarcable, la major documentada fins al moment al jaciment, incloent olles, gerres, plats-tapadores, etc., amb diverses peces senceres. Per tant, estaríem davant de l'espai de la casa destinat a l'emmagatzematge de la vaixella domèstica.

En els nivells vinculats a la planta baixa, el fet més remarcable seria la documentació de les restes de diversos animals morts in situ durant l'incendi. ' També de materials relacionats amb aquesta presència de fauna en aquest espai, destacant un mos de cavall de ferro. Per tant, la hipòtesi més probable és que estem davant d'un espai estabulari.

En relació amb els materials identificats en aquests dos edificis, especialment rellevants serien els materials ceràmics que, juntament amb els recuperats a l'Edifici $\mathrm{D}$, conformen el lot ceràmic més complet mai recuperat a la Cerdanya. Més enllà d'aquests, cal remarcar la troballa d'elements vinculats a les activitats productives, com pondera i fusaioles, i també elements metàl.lics com l'esmentat mos de cavall. Ara bé, els materials més remarcables aparegueren a l'Edifici F. En aquest, en els estrats de destrucció aparegueren dues monedes de plata: una dracma d'Empúries i una imitació gal.la de dracma emporitana. Aquesta troballa és especialment important per a la datació. Així, la recuperació de diversos fragments de ceràmica del Taller de Roses a l'Edifici $\mathrm{G}$, juntament amb una datació radiocar- bònica, ${ }^{10}$ situen de nou l'horitzó de destrucció d'aquests àmbits al darrer quart del segle III aC, donant més solidesa a les dades recuperades a l'Edifici D.

Volem insistir, però, en l'evidència numismàtica, ja que creiem que es tracta d'un dels elements claus per a poder defensar l'existència d'un conflicte bèl.lic que implicà la destrucció de l'assentament de Baltarga en el context cronològic i geopolític de la Segona Guerra Púnica. Així, la recuperació d'un important lot monetari vinculat a l'assentament constitueix una evidència especialment rellevant. De fet, no només podem parlar de les dues dracmes recuperades a l'Edifici F, també tenim una altra dracma emporitana d'imitació gal-la documentada a la part externa sud de l'Edifici D, amb cronologia al voltant de mitjan segle III aC. Per una altra banda, durant la campanya de prospecció amb detector de metalls que es dugué a terme l'any 2017 a la vessant del tossal, es recuperà un destacadíssim lot monetari que, entre d'altres, permeté recuperar un total de tres dracmes emporitanes, una imitació gal.la de dracma emporitana i una fracció de dracma de Rhode. Finalment, a tot això cal afegir la troballa per aficionats de nombroses peces monetàries tant al tossal com a un radi de $3 \mathrm{~km}$ al seu voltant. D'entre aquestes peces, i per aquesta cronologia de segle III aC, podem remarcar la troballa de quatre dracmes d'imitació més i una tetradracma al mateix tossal, una dracma d'argent d'Emporion localitzada al lloc de

9. Aquestes restes encara estan en procés d'estudi, però pel moment podem parlar d'un mínim de quatre individus, incloent com a mínim un parell d'ovicàprids.

10. Realitzada amb restes carbonitzades de l'estrat de destrucció 3213 de l'Edifici F. La datació, feta pel Laboratori de Datació per Radiocarboni de la Universitat de Barcelona, donà un resultat calibrat de BC 391204 (amb una probabilitat de 95\%). Tanmateix, l'únic pic de probabilitat presentava una forquilla compresa en el $2238 \pm 39 \mathrm{BP}$. Considerem, però, que la presència d'altres elements de datació com la ceràmica o les monedes permeten afinar prou per apuntar a aquesta cronologia de darrer quart del segle iII aC. 

de la Segona Guerra Púnica

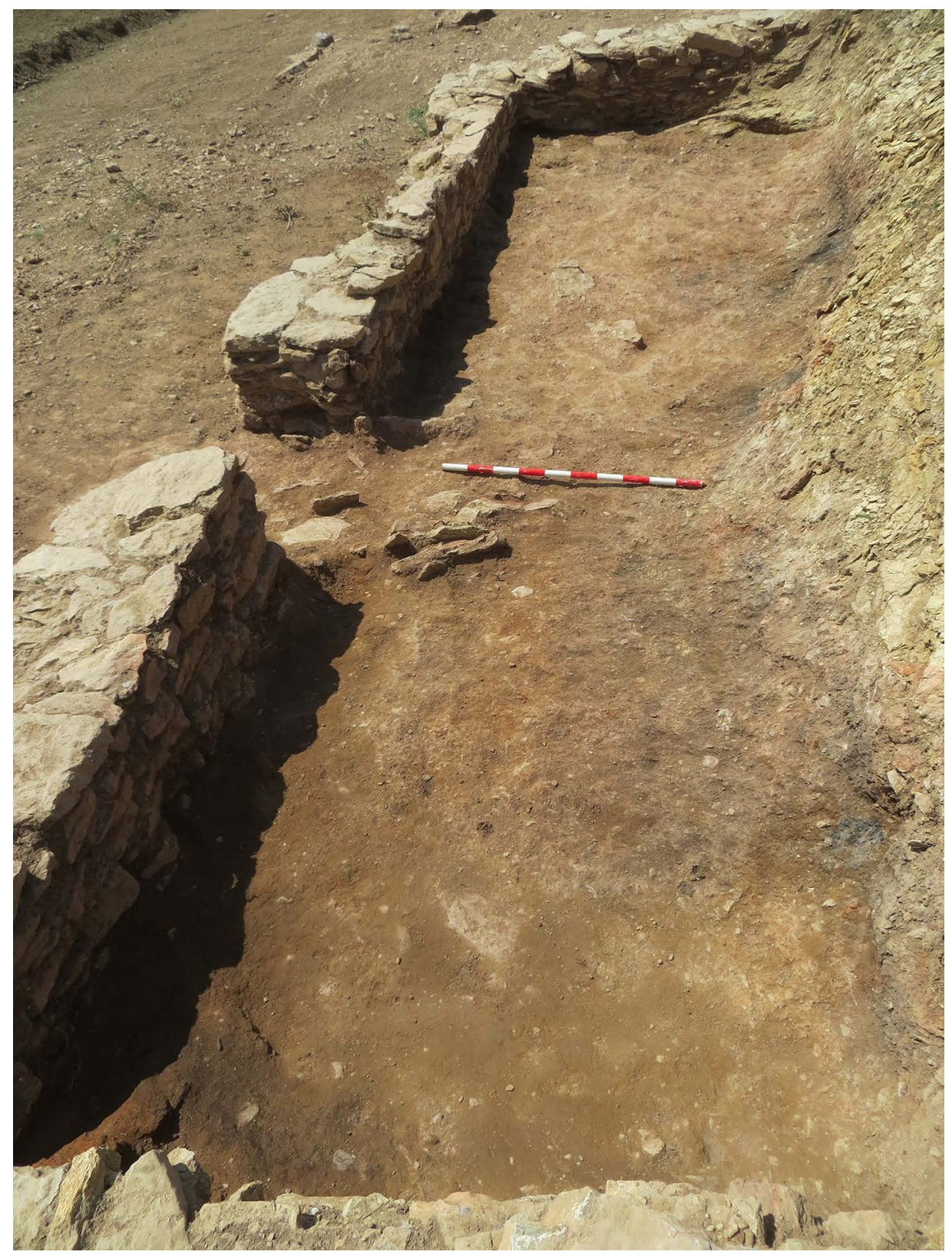

Figura 10. Imatge de l'Edifici G del Tossa de Baltarga des del costat est durant el procés d'excavació dels nivells de la planta baixa (font: autors). 


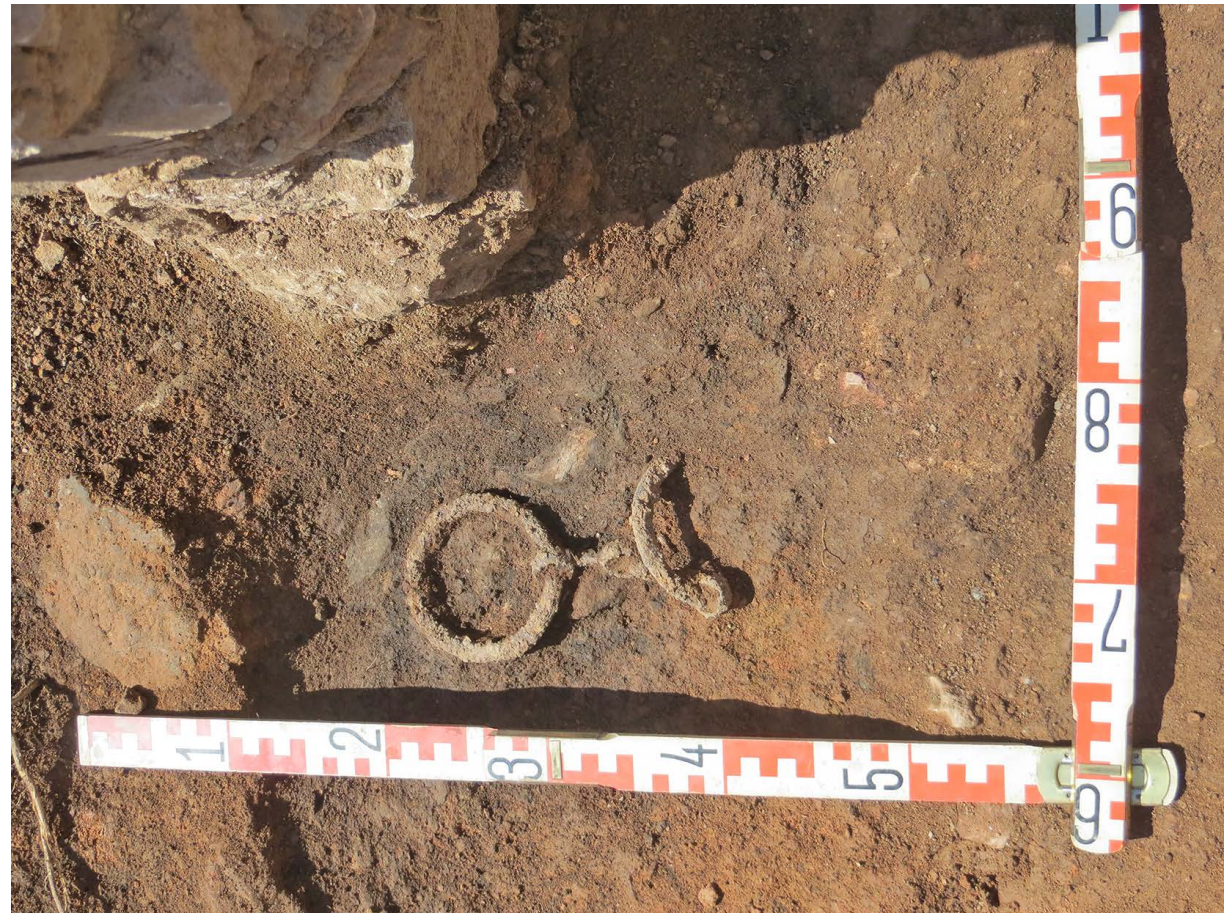

Figura 11. Mos de cavall recuperat a l'Edifici G (font: autors).

Torrelles, entre Prats i Urús, i una tetradracma de Rhode i una altra d'imitació gal.la del cavall parat d'Emporion, ambdues de la zona de Talló (Morera, 2017: 1013). ${ }^{11}$ Aquesta gran concentració de material numismàtic en el jaciment i voltants no creiem que respongui a l'atzar i possiblement s'ha de vincular amb aquesta funció de control territorial del Tossal de Baltarga. Així, seria possible plantejar que aquesta concentració monetària es vinculés a una presència de tropes militars, fos de forma permanent, estacional o puntual en aquest espai.
El principal problema per a poder vincular aquest numerari amb els fenòmens de la Segona Guerra Púnica és que, de moment, no s'ha pogut recuperar cap moneda cartaginesa a la zona. ${ }^{12}$ Per tant, podem plantejar la vinculació de l'abundant presència de numerari amb una presència militar com a mínim puntual a la zona de Baltarga en el darrer quart del segle $\mathrm{III} \mathrm{aC}$, però no tenim evidència directa que permeti parlar de tropes púniques en aquest espai. Altres elements reforcen la hipòtesi de la presència militar, com la troballa, també mitjançant prospecció

11. Aquest lot monetari ha estat estudiat en alguns articles: Campo i Mercadal (2009), García (2016).

12. De fet, a tota la Cerdanya només recentment es documentaria la troballa d'un possible shekel per part d'un aficionat. 


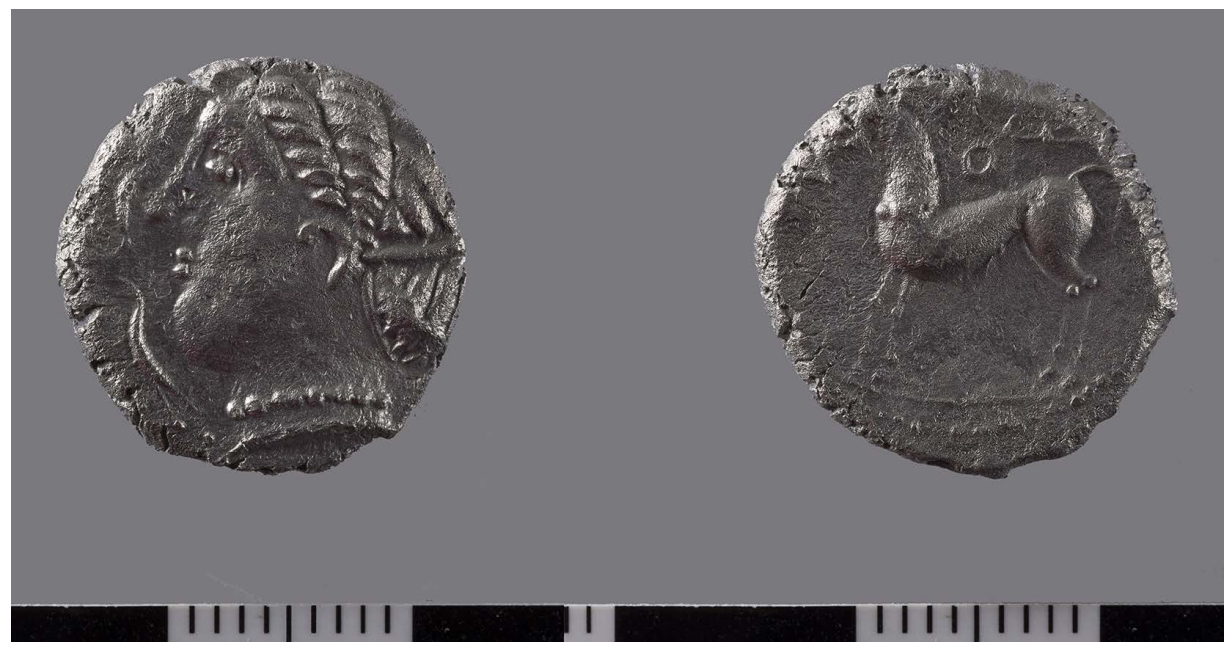

Figura 12. Dracma d'imitació emporitana documentada al Tossal de Baltarga durant la campanya de 2017 (font: Ramón Maroto).

amb detectors de metalls, d'un lot prou abundant de bales de fona de plom, ben reconegudes com a element diagnòstic en relació amb la presència de tropes i fets militars. Malauradament, per al moment l'estudi d'aquestes peces resta pendent $\mathrm{i}$, per tant, no podem fer una aproximació a la seva cronologia.

\section{Interpretació de les evidències arqueològiques: els ceretans i la Segona Guerra Púnica}

Les evidències arqueològiques recuperades al Castellot i, especialment, al Tossal de Baltarga semblen indicar que el moment de finals de segle III i pas al segle II aC a l'àrea cerdana implicà certes convulsions en el model socioeconòmic i territorial. El fet que aquestes modificacions siguin violentes en el cas de Baltarga podrien apuntar a una relació amb els fenòmens militars de la Segona Guerra Púnica. Així, les fonts clàssiques mostren com les tropes d'Anníbal creuaren cap a la Gàl.lia per algun punt dels Pirineus Orientals. No entrarem ara en el debat sobre les fonts, perquè és una qüestió que es tracta amb profunditat en un altre article d'aquest mateix volum. ${ }^{13}$ Ara bé, no creiem que es pugui descartar un pas de les tropes d'Anníbal (o almenys de part d'elles) seguint el corredor del Segre i creuant pel territori cerdà a través del coll de la Perxa per, resseguint el Tet, arribar a les planes rosselloneses. ${ }^{14}$

13. Remetem, doncs, a l'article de O. Olesti en aquest volum. També veure: Morera, 2017: 1178 i ss.

14. Evidentment nosaltres no som els primers a proposar la ruta cerdana en el pas d'Annibal. De fet, diversos autors que han treballat la qüestió també es decanten per aquesta opció (Campmajó i Padró, 1978: 202; Beltrán, 1984; Rico, 1997: 90; Olesti i Mercadal, 2005: 299; Crespo, 2011: 25; Olesti, 1993: 134; 2014, 332-333; 2015, 185; 2016, 168; Revilla i Santacana, 2015: 47). 
Aquest pas, sens dubte, tindria repercussions directes sobre la població ceretana que habitava aquesta regió. Així, només recordem les referències a autors clàssics com Sili Itàlic (Púnica.3.357-358), Polibi (3.35.1-3) o Titus Livi (21.23.2-6; 24.1), dels quals es desprèn clarament una relació directa entre els pobles ibers que habitaven les zones pirinenques i prepirinenques i els contingents armats de tots dos bàndols. En aquest context, doncs, i si acceptem la possibilitat d'un pas de tropes cartagineses per aquesta regió, és l'evidència arqueològica disponible la que ha de permetre contrastar una possible afectació sobre l'estructura socioeconòmica i territorial ceretana.

Així, en el cas de les sitges del Castellot, tot i no ser una evidència tan contundent com la de Baltarga, sí que permet una aproximació molt directe a les possibles conseqüències econòmiques d'una relació amb els fenòmens militars de la Segona Guerra Púnica. De fet, es tracta d'una qüestió ben documentada a altres zones del nord-est peninsular: en el marc dels efectes de la Segona Guerra Púnica i de la revolta indígena dels anys 197-195 aC, es produí un període de destruccions d'oppi$d a$, que anava acompanyat de la fi d'algunes necròpolis, però també d'una gran amortització de sitges. L'obliteració d'aquests magatzems s'havia de relacionar segurament amb les necessitats bèl-liques, logístiques i alimentàries que es generarien en aquell moment, però també amb el trencament de la cadena productiva-excedentària-comercialitzadora que fins llavors havia tingut una gestió molt centralitzada (Olesti, 2000). Exemples d'aquestes amortitzacions els tenim en llocs tan dispars com Pech-Maho (Gailledrat i Gardeisen, 2008), Isona (Belmonte, 2015: 158), Sant Esteve d'Olius (Asensio et al.,
2008) o les Masies de Sant Miquel (Adserias et al., 2002: 255), per citar-ne només alguns que abastin bona part del territori del nord-est. Per tant, tot i la migradesa de les dades, l'amortització de les sitges que tenim ben documentada al Castellot, podria estar perfectament enquadrada en un procés d'estrès bèl-lic ben documentat a la major part de territori català.

El cas, però, del Tossal de Baltarga resulta encara més indicatiu. El fet de trobar un assentament situat en un punt estratègic, clarament relacionat amb el control del territori, amb evidències d'una destrucció violenta en un context cronològic de darrer quart del segle III aC, fa que estiguem, sens dubte, davant de la millor evidència arqueològica documentada fins aquest moment als Pirineus Orientals que es pugui relacionar amb la Segona Guerra Púnica. Més enllà de la destrucció violenta de l'assentament, alguns altres elements són especialment remarcables i, en aquest sentit, cal destacar sobretot l'acumulació de material vinculat amb presència militar com l'important lot monetari i elements com les bales de fona de plom.

Totes aquestes evidències arqueològiques, doncs, què permeten dir sobre els ceretans i la Segona Guerra Púnica? Creiem prou plausible, a partir del relat de les fonts literàries, que la vall cerdana es veiés afectada de forma directa o indirecta pels fets succeïts durant aquest conflicte. Així, és possible que les tropes d'Anníbal, o part d'aquestes, passessin a través d'aquest territori per a creuar els Pirineus pel Coll de la Perxa. Arqueològicament, però, no tenim evidències directes sobre la presència de tropes cartagineses a la zona, tot i que pensem que les dades arqueològiques presentades en aquest treball poden suposar una primera pista cap a la confirmació d'aquest pas. 
Així, el que podem afirmar sense dubtes és que en el context geopolític de la Segona Guerra Púnica, el territori de la vall cerdana patí una afectació des d'un punt de vista socioeconòmic (tal com mostra l'amortització de les sitges del Castellot) i territorial (a partir de la destrucció del Tossal de Baltarga). A partir d'aquesta evidència queda intentar veure qui fou el responsable d'aquest desequilibri, extrem que no podem per al moment confirmar. Tant podríem estar davant d'una intervenció directa de les tropes cartagineses en el seu pas per la zona, com el resultat d'enfrontaments interns entre diversos grups autòctons a conseqüència del trasbals que suposà l'enfrontament entre les dues potències mediterrànies. Així, cal re- cordar que les fonts literàries apunten a una situació política complexa en la qual els pobles pirinencs es veieren plenament immersos, havent de decantar-se per mostrar fidelitat i suport cap a un dels dos bàndols, amb tot el que això significava (i amb la possibilitat de canviar de bàndol amb el temps).

Per tant, creiem que les evidències arqueològiques documentades a assentaments com El Castellot i el Tossal de Baltarga estarien demostrant les conseqüències d'un fenomen bèl.lic d'ordre mediterrani a una àrea muntanyenca com la Cerdanya, tradicionalment considerada com allunyada dels principals esdeveniments històrics del període, però que cada cop veiem més clarament que estava plena-

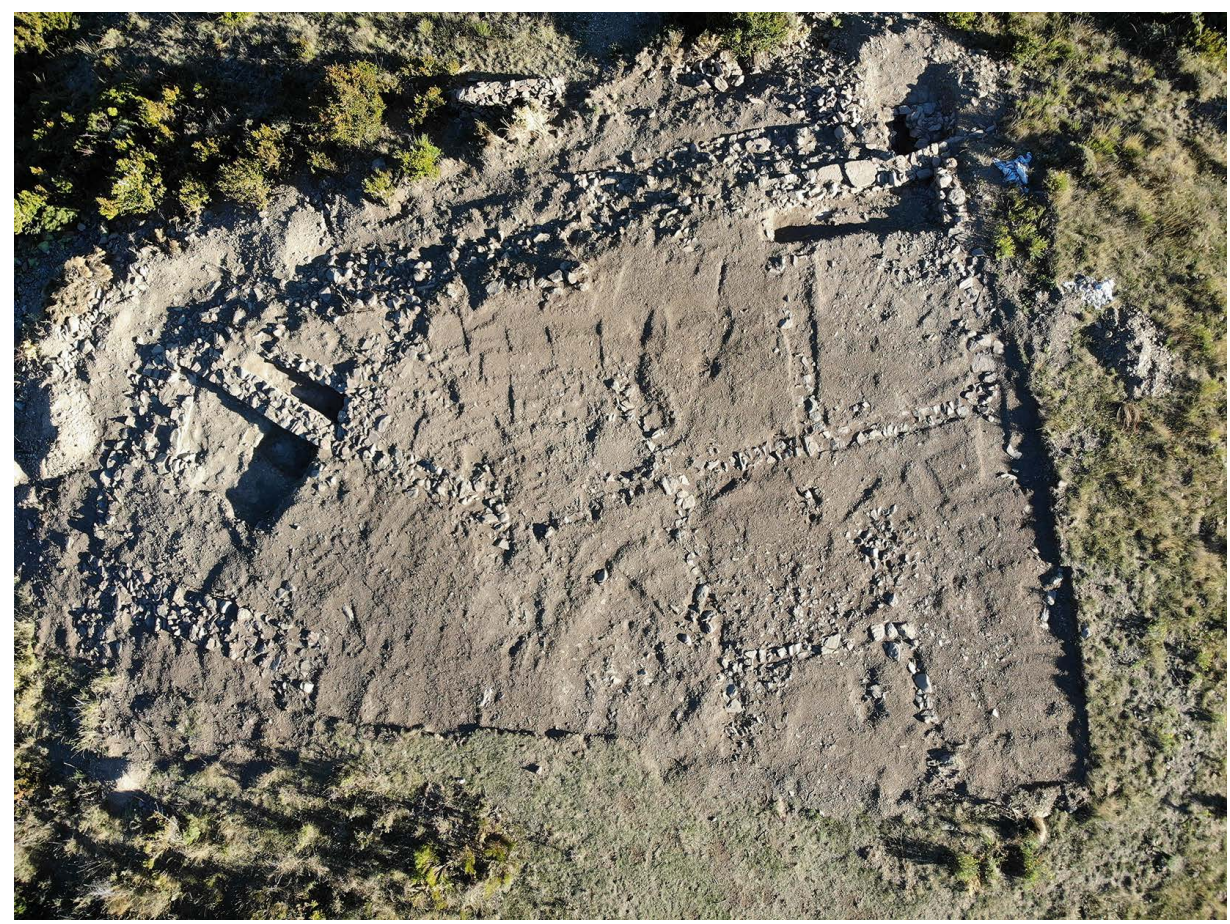

Figura 13. Vista aèria de les estructures documentades al Serrat del Castellar (font: autors). 
ment vinculada amb allò que succeïa a la resta del nord-est peninsular. Encara, però, se'ns escapen molts detalls de com afectaren de forma concreta aquests fenòmens a la regió $i$ esperem que la continuació de les intervencions arqueològiques permetran aprofundir en aquests elements i acabar de discernir el paper dels ceretans en conflictes com la Segona Guerra Púnica.

Per acabar, i com a mostra de la importància de les dades arqueològiques per avançar en aquesta qüestió, en els darrers anys hem iniciat l'excavació d'un nou assentament d'època antiga a la Cerdanya: el Serrat del Castellar, a Fontanals de Cerdanya. Tot i que només s'hi ha dut a terme dues breus campanyes arqueològiques, podem establir que es tracta d'un oppidum: un poblat aturonat que resta defen- sat per un sistema defensiu (fossat i potser muralla) que barra la zona de més facil accés. Des d'un punt de vista funcional, i atenent a la seva posició privilegiada a l'inici de la vall de la Molina, pot molt ben ser que es tractés d'un oppidum vinculat al control d'aquella vall secundària, i en conseqüència, a la via que hi transitava. Per al moment, de forma general i a falta d'una major precisió de les dades, s'hi identifiquen dues fases cronològiques, una d'iberoceretana (s. IV-III aC) i una altra de romana republicana (II-I aC) i en alguns punts hi hauria evidència de nivells d'incendi. Tenint en compte aquest element $\mathrm{i}$ la seva situació estratègica, no podem descartar que en els anys vinents disposem d'un altre exemple que permeti obtenir més dades al voltant de la transició entre els segles III i II aC al territori ceretà.

\section{Referències bibliogràfiques}

Adserias, M.; Cela, X.; Marí, L. (2002). «El poblat ibèric fortificat de Masies de Sant Miquel (Banyeres del Penedès, Tarragona)». Revista d'Arqueologia de Ponent, 11-12, 255-275.

Asensio, D.; Cardona, R.; Ferrer, C.; Morer, J.; Pou, J.; Choren, J.; Calduch, N. (2008). «L'hàbitat i el camp de sitges ibèric de Sant Esteve d'Olius (Olius, Solsonès): un nucli d'activitats econòmiques especialitzades del segle III aC. a la Catalunya interior». Tribuna d'Arqueologia 2007, 149-167.

Belmonte, C. (2015). «El Serrat dels Espinyers: noves aportacions al poblament iber i romà d'Isona (Pallars Jussà)». A: Generalitat de Catalunya (ed.). Actes de les Primeres Jornades d'Arqueologia i paleontologia del Pirineu i Aran celebrades a Coll de Nargó el 29 i 30 de novembre de 2013, 156-163.

Beltrán, F. (1984). «El año 218 aC. Problemas en torno al comienzo de la Segunda Guerra Púnica en la Península Ibérica». A: IEC (ed.). V Congrés Internacional d’Arqueologia de Puigcerdà, celebrat a Puigcerdà del 23 al 25 de setembre de 1982. Puigcerdà, 147-171.

Campmajó, P.; Padró, J. (1978). «Els Ceretans». A: IEC (ed.). II Col-loqui internacional d’Arqueologia de Puigcerdà, celebrat el 3-6 de juny de 1976. Puigcerdà, 205.

Campo, M.; Mercadal O. (2009). "Aproximación a la circulación monetaria en la Cerdanya (siglo iI aC-mediados siglo i dC)». A: Arévalo A. (ed.). Actas del XIII Congreso Nacional de Numismática "Moneda y Arqueología". Madrid, 353-367. 
Crespo, C. (2011). Recepy Pyrenaeum. Estudi històric dels Pirineus en època antiga. Tesi doctoral inèdita. Barcelona: Universitat Autònoma de Barcelona.

De León, D.; Morera, J.; Oller, J.; Olesti, O. (2017). «Los conjuntos cerámicos de las fases de ocupación Ceretana e Ibero-Romana de El Castellot, Bolvir de Cerdanya (Girona)». Cypsela, 20, 165-181.

Gailledrat, E.; Gardeisen, A. (2008). «Assemblages originaux d'équidés de la fin du iII siècle avant notre ère sur le site de Pech Maho (Sigean, Aude)». Association pour le Développement de l'Archéologie en Languedoc, 4, 105-123.

García, M. (2016). «Hallazgos de dracmas emporitanas en Bellver de Cerdanya». Acta Numismática, 46, 77-80.

Morera, J. (2017). Territori i poblament de Cerdanya a l'Antiguitat: la iberització i romanització de la Vall Cerdana. Tesi doctoral. Barcelona: Universitat Autònoma de Barcelona.

Morera, J.; Olesti, O.; Oller, J. (2016). «El control del Pirineo en época ibérica y romana republicana». A: Pera J.; Vidal J. (eds.). Fortificaciones y control del territorio en la Hispania Republicana. Zaragoza, 137-166.

Morera, J.; Oller, J.; Olesti, O.; Viladevall, M. (2017). «La Cerdanya i l'explotació dels recursos naturals en època antiga: el Castellot de Bolvir i el Tossal de Baltarga». Treballs d'Arqueologia, 21-22, 99-127. <https://doi.org/10.5565/rev/tda.58>

Olesti, O. (1993). «La Cerdanya en època antiga: romanització i actuació cadastral». Estudios de la Antigüedad, 6/7, 133-153.

- (2000). «Integració i transformació de les comunitats ibèriques del Maresme durant el s. II-I aC: un model de romanització per a la Catalunya litoral i prelitoral». Empúries, 52, 55-86.

- (2014). Paisajes de la Hispania romana. La explotación de los territorios del Imperio. Sabadell: Dstoria Edicions.

- (2015). «August i els Pirineus». A: López, J. (ed.). Actes del Segon Congrés d’Arqueologia i Món Antic. August i les provincies occidentals, 2000 anys de la mort d'August, vol. 1. Tarragona, 185-191.

- (2016). «Augusto y el control de los territorios pirenaicos». Gerión, 34, 163-190.

Olesti, O.; Mercadal, O. (2005). «La iberització del Pirineu Oriental i la filiació étnica dels ceretans». Acta Paleohispanica, 5, 295-314.

Olesti, O.; Morera, J.; Crespo, C.; Mercadal, O. (2011). «El Castellot de Bolvir (la Cerdanya): una fortificació ceretana als Pirineus». Tribuna d'Arqueologia 2009-2010, 295-330.

Olesti, O.; Morera, J.; Oller, J.; Mercadal, O. (2016). "Un nou assentament iberoceretà i romà a la Cerdanya. El Tossal de Baltarga (Bellver de Cerdanya, Cerdanya)». KER, 6, 61-66.

- (2018). «Paisatge i territori a la Cerdanya antiga: novetats arqueològiques al Castellot de Bolvir i al Tossal de Baltarga». Tribuna d'Arqueologia, 2015-2016, 132-156.

Oller, J.; Morera, J.; Olesti, O.; Mercadal, O. (2013). «El Tossal de Baltarga: un nou assentament iberoceretà a la Cerdanya». A: Generalitat de Catalunya (ed.). Primeres Jornades d'Arqueologia i Paleontologia del Pirineu i Aran (Coll de Nargó, 29-30 de novembre de 2012). Lleida, 58-65.

Oller, J.; Olesti, O.; Morera, J.; Mercadal, O. (2018a). «Los ceretanos y la iberización del pirineo oriental (s. IV-III ane). Una nueva aproximación histórica y arqueológica». Archivo Español de Arqueología, 91, 183-204. $<$ https://doi.org/10.3989/aespa.091.018.009>

Oller, J.; Olesti, O.; Morera, J.; Mercadal, O. (2018b). «El Tossal de Baltarga (Bellver de Cerdanya, Lleida): un nou exemple dels processos d'iberització i romanització a l'àrea pirinenca». Revista d'Arqueologia de Ponent, 28, 31-45.

Principal, J.; Asensio, D. (2006). «Relaciones comerciales Roma-Hispania. La Hispania Citerior en el siglo II aC». A: Burillo, F. (ed.). Segeda y su contexto histórico. Entre Catón y Nobilior (195-153 aC). Homenaje a Antonio Beltrán Martínez. Mara, 117-140. 
Pons, E.; Llorens, J. M. (1991). «L'organització de l'espai domèstic a Puig Castellet. Lloret de Mar - La Selva». Cypsela, 9, 95-110.

Revilla, V.; Santacana, J. (2015). Catalunya Romana. Barcelona: Rafael Dalmau.

Rico, Ch. (1997). Pyrénées romaines. Essai sur un pays de frontière (IIlème siècle avant J.C - IVème siècle ap. J.C. Madrid: Casa de Velázquez. 